\title{
RENÉ VAN HUFFEL, UN PRIVILEGIADO PUENTE CON LA CULTURA DE HABLA FRANCESA
}

\author{
Victor Valembois \\ Catedrático retirado de la Universidad de Costa Rica
}

\author{
Recibido 4-II-2004 • Aceptado 9-03-2004
}

\begin{abstract}
Cuando uno vive en una cultura totalmente ajena, se tiene que hacerse un poco "el otro" para entenderlo: entonces se rompen los dogmatismos, se someten a prueba las convicciones más arraigadas, jamás cuestionadas, y se produce un proceso de democratización interna.
\end{abstract}

Antonio Skármeta (Áncora, 10.03.96)

Para el Dr. Gonzalo Vargas, alumno de don René. Europa dio mucho a través de ustedes dos. Ambos entregaron lo mejor de sí mismos a Costa Rica.

\begin{abstract}
Resumen: Nunca lo conocí, pero su foto entre los eméritos en el Auditorio de la Facultad de Educación me picó la curiosidad: a base de entrevistas y lecturas confeccioné una biografía de un personaje cuya modesta e incompleta semblanza quizá incite a reflexionar sobre un modelo de profesorado y además sugiere, ojalá, que no solo en este caso, por la enseñanza de un idioma, sino por lo universitario bien entendido en tiempos de globalización, conviene tener una mente abierta a la interferencia cultural, al matiz filológico: confío que esta reconstrucción, no hagiográfico sino profundamente humanista, tenga valor de rescate, hacia el pasado y tenga utilidad, hacia el futuro.
\end{abstract}

Palabras clave: Enseñanza de Idiomas, Intercultural, Bélgica, Diferencia.

\section{1. “Apuntamientos para una biografía"}

Costa Rica les debe mucho a varios maestros europeos. Pienso en un Henri Pittier, en Constantino Láscaris, Teodoro Olarte y algunos otros. Cruzaron el Atlántico para no volver a su tierra natal. Convivieron con diversas generaciones de discípulos. Merecen el calificativo de educadores, porque lo fueron en el sentido más usual, pero además en la acepción dirigista del término: mostraron el camino. Por su ejemplo paciente, en una especie de ósmosis, aplicada a lo cultural, provocaron una corriente. Decidieron quedarse y fueron enterrados como propios, acá. Lograron el cambio esencial: comprometer cantidad de pupilos hacia ideales superiores. Los consideramos dentro de una galería de grandes, no solo por la valiosa transmisión de conocimiento en sus respectivas materias, sino también por la proclamación y la vivencia de cierto humanismo inasible. Fueron Maestros, con mayúscula, y la crisis en la que su 


\begin{abstract}
I never met him in person, but his picture in the Gallery of Emeritus Professor at the School of Education called my attention due to his typical Belgian name. I started searching for information about him and his life to construct a kind of biography. This incomplete and modest reconstruction of his accomplishments shows a model of language teaching. It is also an example for the concept of university in times of globalization, well understood to intercultural interferences and the philological connotation: I hope that this reconstruction, not hagiographic but deeply humanistic, serves both as a rescue effort considering the past and as a useful tool while looking into the future.
\end{abstract}

Key words: Study of foreign languages; Intercultural, Belgium, Differences. patria de adopción se suma ahora se debe, entre otros, a una falta de tales propulsores. Uno de esos fue René Van Huffel.

Desde que vi su foto en la galería de profesores eméritos en el auditorio de la Facultad de Educación, en la Universidad de Costa Rica, con todo y su otro apellido "extraño", sentí la necesidad de ahondar en el conocimiento de esta persona y esa personalidad, de las que pronto me repitieron beldades y bondades. Lo hice mío y el trabajo a continuación constituye un modesto, no tanto por tener el mismo origen nórdico, sino porque cuanto más avanzaba la investigación, se me puso en evidencia que merecía, más que un recuerdo fotográfico, una saludable memoria de la patria, la de Costa Rica y la del mundo. Con énfasis en la enseñanza de la cultura y la lengua de habla francesa, Van Huffel entregó prácticamente medio siglo de su vida a ser un puente entre la vieja Europa que dejó y este subcontinente joven que adoptó.

Si Monseñor Sanabria le puso "apuntamientos" a su trabajo grueso y sesudo, ¿cómo se permitirá este monaguillo de la historia un nombre más pomposo para estas cuartillas? Falta información y precisión para una biografía más completa que, sin duda, como obra de rescate en la relación tico-belga, se merece aquel Quijote de por allá, aterrizado en tierras tropicales. En el siglo XX hubo por lo menos otra media docena de destacados profesores de francés, de origen belga ${ }^{1}$, entre todos han dejado su huella en la enseñanza de esa lengua en el país, junto con francófonos y francófilos de Francia (y es conveniente no meter todos esos docentes en un mismo saco "francés" como suele hacerse). Como sea, aquí va un rescate para el principal de todos ellos.

Aunque Van Huffel haya fallecido hace solo treinta años y a pesar de disponer el suscrito de cantidad de informantes orales, he allí justamente una dificultad. $\mathrm{Pa}$ rece mentira que siendo un tema de gran parte del siglo XX hayan quedado tan pocos elementos escritos al respecto: si bien el 
docente formó centenares y hasta miles de alumnos en francés, salvo contadas excepciones, la metodología utilizada en esas décadas era esencialmente oral (fuera de un manual que procederé a analizar). Don René no dejó tampoco estudios teóricos ni contribuciones académicas como ahora es de rigor.

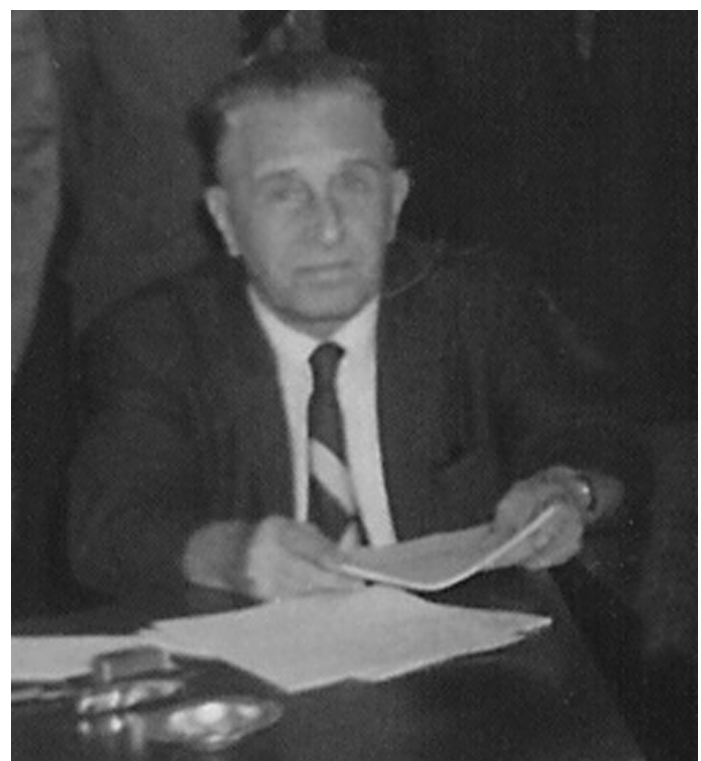

René Van Huffel. Fotografía propiedad del Archivo de la Universidad de Costa Rica.

En aras de salir de este impasse, en lo metodológico me he basado al máximo en documentos escritos así como en informantes de categoría, muchos de ellos colegas retirados. Por otro lado, he agrupado la información por décadas, dando a cada una la relevancia de un informante principal. Así, para los años veinte y treinta me orientan el Dr. Vargas y su esposa; para la década de los cuarenta, me guía sobre todo la excelsa profesora Hilda Chen Apuy; en los cincuenta, la profesora Marie Thérèse de Urruela; respecto de la siguiente década, a golpe de correo electrónico me asistió sobre todo Jack Wilson. Pero en el coro de testigos también figuran, por ejemplo Marco Tulio Salazar y su hija, Manuel Antonio Quirós,
Rolando Mendoza y otros, no menos de una docena en total, entre hombres y mujeres, nacionales y extranjeros, profesores y alumnos. A todos ellos, felizmente sobrevivientes lúcidos, a pesar de la edad y algunos problemas físicos, de verdad, un gran agradecimiento. Este proceder permite entonces evocar al maestro en sucesivas muestras palpables, etapas en su tránsito por el mundo. Destacan desde luego permanentes rasgos de carácter y de estilo, por lo que al lector atento no le sorprenderán algunas repeticiones en forma de insistencia. A su vez, y no lo niego, puede ocurrir que por este enfoque en círculos concéntricos, aparezcan cambios y hasta contradicciones a partir de lo que reportan los informantes, pero pregunto: ¿no resulta toda vida una interferencia entre ciertas constantes, felizmente junto con varias evoluciones?

\section{Huellas anteriores a Costa Rica}

René Van Huffel Dedobbeleer nació en Bruselas, el 29 de enero de 1900. No se dispone de mayor información respecto de calidades de sus progenitores ni de estructura familiar, sus estudios pre-universitarios, etc. Por supuesto, los dos apellidos tienen neta resonancia flamenca, es decir, originarios de Flandes, la parte norte de Bélgica, pero de allí a asegurar que su idioma (el de la casa y de la escuela) haya sido primero el flamenco (mejor llamado neerlandés) sería una deducción prematura. Por otro lado, por los estudios posteriores, sí, es muy probable que cursó la secundaria "clásica”, es decir con latín y griego hasta en la sopa (y el suscrito no se queja de este brebaje). Teniendo en cuenta su fecha de nacimiento, tiene que haber estado en lo que aquí se llama el colegio en los años que corresponden a la Primera Guerra Mundial.

Muchos años después, en su expediente de la Oficina de Personal, en la Universidad de Costa Rica, se señala que 
era bachiller y candidato (egresado) de la Facultad de Filosofía y Letras de la Universidad de Bruselas. Allí mismo se menciona su condición de "Profesor de Estado": en términos costarricenses, significa que también aprobó los cursos de didáctica, aparte de la carrera, destinados a los que postulan por la docencia. No consta ningún tipo de reconocimiento de estudios ni de ese título de profesorado, pero por los años y el prestigio que se ganó aquí, entre colegas como entre pupilos, dejó sobradamente llena esta laguna.

Fotografía propiedad del Archivo de la Universidad de Costa Rica.

Varias pistas orientan hacia una vocación pacífica y antibélica que pronto lo haría salir de Europa. Varios indicios apuntan hacia una condición que ahora llamaríamos de "objetor de conciencia", aunque algún informante cree saber incluso que se trataba de un desertor ${ }^{2}$. Según el ex alumno Otto Coin, "nos enseñó todos los trucos habidos y por haber para evitar el servicio militar". Se refiere por supuesto a la Primera conflagración planetaria. En Bélgica, entonces, ese deber patriótico era selectivo, con base en una serie de criterios. Los pudientes podían comprar su dispensa, mientras otros, menos equipados en la billetera, fingían enfermedades, etc. También les narró una anécdota de la misma contienda: confrontada con escasez de carne, como en todas partes, la gente empezó a comer hasta canino. Su padre consiguió un pedazo de vacuno. Al preguntársele por el perro de la casa, René bromeó que lo estaban comiendo; su papá, muy riguroso, se enojó. Los dos episodios reflejan, por un lado, el fuerte impacto que causó en el adolescente esa horrible guerra de trincheras; por otro lado confirman un temperamento antimilitar. Por allí se aglomera una serie de razones que empujaron al joven a cruzar el Atlántico.

No vino directamente a Costa Rica, sino mediante estadías, en otra parte. El citado expediente también refiere a una Licenciatura en Letras en la Universidad de Montpellier, Francia, pero aquello no aparece suficientemente documentado: puede haber estudios, pero no hay grado. Según la nomenclatura costarricense tan querida, habría implicado además que todo el mundo lo hubiera tratado por su título, lo que no fue el caso. Por otra parte, la hipotética salida de Bélgica vía este lugar del sur de Francia debe haber sido rápida: a los veintitrés años don René se encuentra entre nosotros, según algunos indicios habiendo pasado también por Estados Unidos y México ${ }^{3}$.

Quedan muchas interrogantes, ojalá esta misma lectura contribuya a soltar recuerdos de los mismos discípulos y allegados. Soy como el Comisario Maigret, de nuestro compatriota, escritor de novelas policíacas, solo que en vez de "chercher la femme", aquí me dedico a "chercher l'homme" y si a Simenon se le identificó algunas veces como "policía del alma", a Van Huffel se le puede calificar como "docente del alma". Un 
posible anzuelo tico, según mis antenas, es que en 1910 murió F. Van Dyck, Cónsul de Costa Rica en Amberes, Bélgica y el señor A. Van Huffel que ocupa la misma residencia, cesó sus funciones de Vice-Cónsul. Partiendo de este nexo probablemente familiar y la existencia también en Costa Rica de una familia Van Dyck, puede haber por allí un puente. Tiene que haber un vínculo explícito, porque normalmente, sobre todo en estos años, un belga ni ubica Costa Rica en el mapa ${ }^{4}$.

\section{Los años veinte, no tan locos}

La primera referencia documental en cuanto a Van Huffel acá se sitúa a principio de los años veinte. En mayo 1922 viene concretamente una misión comercial de este país, entre otros a Costa Rica y al parecer don René algo tuvo que ver con ella. El Sr. Georges Rouma es el jefe de la misión económica cuyo objetivo principal y urgente consiste en encauzar vínculos comerciales latinoamericanos para este país europeo, totalmente maltrecho por la injusta guerra ${ }^{5}$. En 1923-24 existe en Bruselas una Cámara de Comercio Belga-Latinoamericana ${ }^{6}$. Manuel María Peralta (Ministro Plenipotenciario, gran enlace entre los dos países, desde varias décadas entonces ya y por una más) forma parte del comité de honor.

Pese a esa labor de enlace, Van Huffel no llegó con fines comerciales. Caso contrario, lo habría hecho solo o asociado por ejemplo con Rodrigo Gómez, largos años residente en Bélgica, a quien sin duda conoció, ya con su agencia de importación, llamada precisamente "Belga" en pleno San José. No vino a hacerse la América, como otro compatriota empresario; pienso en Max Coin de Levin7; tampoco contratado por ninguna empresa de acá, como sí lo fue su coterráneo Paul Deliens (a quien debe haber conocido en Cartago): un gran intelectual, pero que se dedicaba a ello fuera de su labor de supervisión de carretera; por último, para nada lo vemos llegar en circunstancias extrañas, como el más conocido: Julio Van der Laat. La información sobre su corta misión "diplomática” señalada en el párrafo anterior, no deja dudas que las mismas autoridades belgas no tenían inconveniente en su presencia acá. Se contaban con los dedos los belgas residentes entonces acá y no se sabe de contactos suyos con ellos, excepto con Loots 8 , compatriota y reformador de las bandas militares. Pero éste, don Francisco, había sido contratado oficialmente por el gobierno (vía el mismo Peralta), en cambio Van Huffel vino a título privado. De manera que ocupa un lugar especial, en perfil también único. Era hombre de ideas vivas y de trato con gente, no de trasiego de materia inerte. Eso llenó su vida. Por otro lado, a falta de pruebas contrarias, lo más probable es que vino solo 9 .

A mediados de los años veinte ya vemos a don René en la actividad que caracterizaría el resto de su larga e interesante existencia: el apostolado no religioso, sino docente. Fabio Fournier, Bachiller del Liceo de Costa Rica en 1923 (o 1925?), conoce allí a René Van Huffel. Pese a más de medio siglo transcurrido, lo recordaba vivamente y con gratitud el Doctor Gonzalo Vargas. La relación entre este profesor y su discípulo era de amistad: iprovechosa ósmosis pedagógica! Vargas, por años eminente médico anestesista y homeópata, guardaba la imagen del docente en este sentido. Se explica en parte porque tenían casi la misma edad. Me los imagino, el belga flaco, sin ser alto, más erguido que muchos, prototipo más bien germánico, frente a su discípulo muy bajito, de rasgos físicos eminentemente latinos. Pero como en toda docencia, el Hombre de la mancha mucho aprendió también de su escudero, entre otros esa sabiduría del pequeño: ¡los hombres se miden de los hombros para arriba! "Chalito" (porque se le podía hablar con cariño), lo recordaba como maestro de una 
cultura extraordinaria, de esos que ensanchan las pupilas. En efecto, la enseñanza de un idioma, ¿no debería ser forzosamente además la de una aguda sensibilización por una cultura, unos valores y por ende una visión de mundo?

Tiene que haber sido antes de 1926, año en que el joven Vargas se fue a estudiar a Bruselas. El profesor de francés en el Liceo de Costa Rica les habló largo y tendido del ferrocarril transiberiano. Toda la clase pasó "volando" en eso. El educador cayó en la clásica trampa de los alumnos: a fuerza de pregunta y pregunta escabullaron nueva materia. Más bien, para el incipiente docente significó un estupendo ejercicio de español. Pero, ¿qué importa esa clase "perdida"? A tantos heredianos, josefinos y "cartagos", este hombre ya bastante viajado y con "mundo" en su cabeza (y en las piernas), les abrió la ventana grande. No era todavía la de Windows 98, pero de todos modos esos imberbes quedaron marcados de por vida.

Otro de esos jóvenes fue el Dr. Carlos Mena Ugalde, fallecido en el año 2000. Cuenta que Van Huffel sobrepasó su papel de maestro para asumir el de orientador y consejero. Si el joven Mena salió en 1927, igual hacia Bruselas, pese a tener contactos en Estados Unidos, fue por influencia e insistencia de don René directamente con su padre, a quien visitó varias veces en su comercio ${ }^{10}$, para convencerlo. Prevalecían en él criterios de selección de los mejores costarricenses. Había que estimularlos con una confrontación en el exterior; pesaba además un criterio de idioma y por ende de inserción cultural. El docente, por lo demás podía comparar. Entre tantos, tenemos así por lo menos dos futuros galenos de la "gloriosa generación de profesionales formados en Bélgica, que tanto y tan bien colaboró en el desarrollo científico de nuestro país" (según el acertado decir de Marta Castegnaro11). Llegaron allí por su profesor de por aquí ... y de por allá.

Durante décadas entonces Don René funcionó como una auténtica correa de transmisión cultural entre sendos continentes. No había ni embajada de Bélgica, menos un Agregado Cultural, de Prensa y Cooperación... pero allí estaba Van Huffel! En ambos casos comentados, se acoplaba al sistema local de becas, pero en sendas oportunidades su sugerencia fue cortésmente rechazada por los padres: orgullosos, argumentaban que podían sufragar esos gastos. Tanto los progenitores de Vargas, como los de Mena eran gente de comercio, lo cual les permitía colaborar con esfuerzo propio. Por lo demás, era socialmente algo mal visto aprovecharse de los recursos del Estado. ¡Los tiempos han cambiado!

Según Carlos Mena, el educador y sus discípulos pudieron verse por lo menos una vez en Europa, concretamente en el lugar de nacimiento del primero y de estudio de los segundos: detalle de lealtad, porque el profesor podría haberse limitado a ver a su familia, en 1930. De regreso, a bordo del buque Magdalena de la línea naviera "Hamburg Amerika" hacia Puerto Limón, en la lista de pasajeros consta en efecto que iba "Van Huffel, René, 28 años" (cuando ya tenía treinta) ${ }^{12}$. La prueba se encuentra en el archivo a nombre de $\mathrm{Ma}$ nuel María Peralta. No me consta contacto ni epistolar ni personal entre éste y Van Huffel, pero en un extraño cruce, del primero, siendo tico en Bélgica, del segundo, siendo belga aquí, de seguro habrían congeniado en lo personal, además de trabajar codo a codo en pro de más de una conveniencia intercontinental.

Doña Lía, la futura esposa del citado Dr. Vargas, señala que Van Huffel le enseñó francés en el Colegio San Luis Gonzaga de Cartago. Clases y más clases, desde el principio, y hasta el final, ese es el castigo de Sísifo que se nos receta a todos los educadores. Pero ¿cómo? Porque la metodología también cuenta, como no. Con base en una certera observación del historiador Meléndez, respecto de un libro en este sentido, apareció en San Ramón. Que lo diga el Comisario Maigret, toda investigación 
es agotadora, pero gratificante con su sujeto en casos como éste: del Maestro se conoce una única publicación, clave para desentrañar su manera de proceder en lo profesional. Según datos de la portada, se trata de un "Método de Francés por René Van Huffel, recomendado por la Secretaría de Educación Pública para uso en los colegios de segunda enseñanza, Imprenta Trejos Hermanos, San José, Costa Rica, 1928”. Va con una carta dirigida al entonces Ministro de Educación y firmada por el Dr. Guillermo Padilla Castro. Volveremos a encontrar este nombre más abajo. Por ahora retomo de él únicamente que este trabajo "viene a llenar un verdadero vacío que hemos sentido cuantos hemos practicado el profesorado de francés"13.

Pero dejemos mejor que sea el autor el que, mediante su introducción, oriente en cuanto a líneas matrices del trabajo: se trata de suplir la ausencia de un texto oficial, para "cubrir todas las necesidades del curso inferior de lenguas". El cuerpo del trabajo no tiene media palabra en la lengua de Cervantes, nada de gramática teórica; tampoco listas de vocabulario. Se basa en cincuenta y cinco diálogos cortos, todos con una sencilla orientación temática, a base de un juego dinámico de preguntas y respuestas. En contra del endoctrinamiento ex cátedra, el conjunto está centrado en el alumno. Empieza con una situación vivencial, directamente del aula, donde de entrada el profesor se presenta: "Je suis Monsieur Van Huffel. Je suis le Professeur de français". De allí se amplía el círculo hacia el colegio, pasando por la calle, hasta llegar a conversar sobre un viaje a Nicaragua. Las escenas se ubican en el contexto real del educando, pero resultan evidentemente todavía adaptables. En este caso, por ejemplo, al inicio se menciona el nombre de autoridades concretas, como "Monsieur Lachner (...) le Directeur du collège, para literalmente casi, abrir la ventana (a la que se alude), y ubicar cerca "le Collège des Demoiselles" (el Colegio de Señoritas...), que desde luego, y en eso no ha cambiado nada, no dejaba de ser más apasionante que la mejor clase participativa del Monsieur...

El autor menciona haber redactado su investigación siendo "fruto de varios años de práctica como profesor de lenguas y más que de práctica, de observaciones tomadas durante los viajes que he hecho", pero no da detalles al respecto. Frente a los odiosos recetarios de vocabulario y de no menos tediosa gramática de éste tipo de manual, el de Van Huffel constituyó toda una renovación que anticipa los ahora clásicos de Assimil... pero el reloj de la historia estaba entonces apenas en la segunda administración de don Cleto González Víquez.

Tengo para mí, además, otro antecedente: la didáctica activo del Dr. Ovide Decroly, pedagogo belga fallecido en 1930. En efecto, si uno observa con cuidado, por un lado el enfoque centrífugo, del alumno hacia el mundo en ámbitos cada vez más amplios y por otro lado conoce la técnica de los "centros de interés" del maestro, se establece el sorprendente enlace. Decroly fue profesor directamente de don Marco Tulio Salazar, como también indirectamente de Brenes Mesén, Omar Dengo y la Niña Emma Gamboa, entre otros ${ }^{14}$. Más que en el manual, se me figura que es en su peculiar estilo donde se perfilaba lo que su discípulo don Marco Tulio condensa como "el efecto del afecto"15: una didáctica que quizá solo coincide con la del Maestro Decroly, sin realmente poder postular una regla de causa a efecto. De todos modos, constituye hipótesis digna de retomar por un graduando de la Facultad de Educación, porque demasiado se ha circunscrito la influencia de Decroly a la enseñanza primaria, cuando en realidad en toda América Latina y en los años treinta a cincuenta, su enfoque obedece a una filosofía del binomio enseñanza-aprendizaje.

En medio de esta febril actividad docente, existen pruebas también de pronta incorporación civil de don René en su nuevo 
contexto nacional: el matrimonio y la naturalización son signos evidentes de voluntad en este sentido. Los dos se cristalizan en esta primera década: como tantos otros, René Van Huffel se hizo "criollo", en el sentido de que se incorporó acá; tampoco él pudo escapar al embrujo del casamiento intercultural: formó matrimonio con la muy tica Victoria Madrigal Araya, Directora de la Escuela del mismo apellido. El 21 de abril del 27 fallece doña Vitalia, su cuñada ${ }^{16}$. Doña Victoria y don René tuvieron una hija, Fanny, que vive en Estados Unidos. De seguro que este enlace le facilitó el otro paso de incorporación: por acuerdo ${ }^{\circ} 213$ del 25 de noviembre de 1929, emanado del Ministerio de Relaciones Exteriores, se le concede la nacionalidad17. Figura como "Mayor, casado, Profesor de Segunda Enseñanza". En la medida en que no había doble ciudadanía legal, este paso voluntario implica, automáticamente en este caso, la pérdida de derecho al pasaporte de origen. Pero don René no tenía la identidad sólo en los papeles, ni se limitaba a una ciudadanía belga de nacimiento: avant la lettre, casi, era europeo por convencimiento además de ciudadano del mundo por vocación: otro rasgo que lo identifica con Erasmo.

\section{Los años treinta: cine y más clases}

Esos años treinta en Costa Rica deben haber sido de una rica experiencia contrastiva: por un lado un San José aldeano, todavía coqueto pero con fuertes diferencias sociales, por otro lado la poca intelectualidad, muy bien formada, europeizante. René Van Huffel ya no figura como extranjero ${ }^{18}$. Pero, iqué riqueza internacional, envidiable para el momento actual! Allí se señala también que "No hay leyes especiales referentes a esos profesores, sino que algunos han llegado al país mediante contrato y otros, radicados desde hace tiempo, sirven el puesto en idénticas condiciones a los nacionales". Ese era, seguramente también el caso de Don René.

Siempre con el permiso del guía Simenon, descubramos ahora otra faceta de René Van Huffel: su intervención como detective en "El retorno", la primera película costarricense, de 1930. Conviene conocer esta joyita, por su frescura, su técnica, sus estampas del San José y su entorno de hace más de seis décadas. El Edificio Metálico, el Teatro Nacional y la fuente del "niño con ganso" (esta última, que ahora figura frente a la Biblioteca principal de la Universidad de Costa Rica) constituyen tres elementos filmados con una característica en común: provienen enteramente o en parte de estructuras metalúrgicos importados de Bélgica. Curioso este aspecto polifacético de Don René, porque ¿cómo meterse en la cabeza de este hombre de ciudad, educado en la culta Europa, al ver estas complicaciones de aldea? Bruselas, la capital del Reino de Bélgica, de donde era originario, tenía entonces prácticamente tantos habitantes como toda la República de Costa Rica.

Surge otra hipótesis interesante a desarrollar: René Van Huffel tendría un papel destacado en el origen del cine costarricense. Él ya estaba en contacto con Walter Bolandi ${ }^{19}$. Aparte de éste, a base de un concurso, había un guión. Pero faltaba un director. Van Huffel había conocido al Sr. A. F. Bettoni en París, en 1929 y logró convencerlo para cruzar el Atlántico, contactándolo el primero con Mario Urbina, empresario teatral y gerente de cine, entre otros del Cine Variedades. Allí empezó la gran aventura ${ }^{20}$. Walter Bolandi era el operador y fotógrafo principal y, según rezan los créditos de este memorable trabajo Junto con su actuación, Don René fue el asistente de dirección ${ }^{21}$. Una pregunta sin resolver: ¿hasta qué punto contribuyó aquí la industria belga (la Gevaert, de la que la familia Trejos, los de la actual imprenta, era representante) a la cinematografía local? Por cierto, un detalle: en el programa original de la película, su 
esposa Victoria Madrigal, aparece como "Victoria Van Huffel", a la usanza europea y no como "de Van Huffel", como sería de rigor en el código local.

Don René siguió trabajando en "el viejo Liceo", como cariñosamente lo llamó don Isaac Felipe Azofeifa. Igual el Dr. Edgar González Campos, entonces Profesor de Castellano, que lo tuvo de colega. Lamentablemente ya ellos se nos escaparon para hacernos la pintura mental del educador. A sabiendas de que José Basileo Acuña, costarricense voluntario en la Primera Guerra Mundial, también fue profesor en esa institución, ¿conversaron sobre ello? Sospecho que ambos, "eurófilos" y francófilos, pueden haber renovado el diálogo medieval sobre las armas y las letras...

\section{Los años cuarenta: clases y activismo aliado}

Pero ya se oía el rugir de la Segunda gran guerra. Van Huffel trabajó mucho para la causa aliada. "La última lección de francés", uno de los "Contes du Lundi22" de Alfonso Daudet, pareciera ser de aplicación. $\mathrm{Su}$ actividad en el "Comité France-Amérique" 23 durante el conflicto, en programas de radio, desde luego señala lucha por la causa aliada, pero a su vez, puede confirmar, décadas después de su llegada huyendo de paralelo conflicto, que sigue luchando por la paz: "si quiere la paz, lucha por la paz": Van Huffel encarna la antítesis al famoso lema latino. Por esa labor le dieron una condecoración francesa.

En el Libro Azul de 1940 figura una foto de una:

importante reunión (del comité en cuestión), con objeto de encauzar los trabajos destinados a prestar ayuda a los refugiados belgas. Concurrieron numerosísimos elementos de nuestra sociedad, preocupados por la suerte que corren los refugiados belgas. En la foto de la izquierda puede verse al doctor don Guillermo Padilla en los momentos en que hacía uso de la palabra 24 .
Este último había estudiado en Bélgica y junto con Calderón, es de los propulsores de la seguridad social aquí, en parte sobre modelo de allá. De seguro que entre los "más de doscientos asistentes" estaba Van Huffel. De fijo también él conocía y apreciaba a Ivonne Clays, la Primera Dama de entonces, la cual, igual que el profesor, tenía fuertes vínculos familiares todavía en su tierra de origen, especialmente en el eje Bruselas-Amberes ${ }^{25}$.

He afirmado y demostrado una voluntad de inserción de René Van Huffel en la realidad local; al mismo tiempo, por sus vínculos con Loots, igual, muy probablemente con Doña Ivonne y, recién, con la resistencia anti-nazi. Lo que me llama la atención, sin embargo es por qué no aprovechó de colaborar con el Repertorio Americano. Como he podido escudriñar también, la revista de don Joaquín García Monge constituía, desde el principio un bastión antibélico, con énfasis en la tierra de Van Huffel $^{26}$. La revista se caracteriza además por una marcada tendencia europeísta y una notoria predilección por el francés. Al contrario de su compatriota Paul Deliens, quien allí publicó más de un artículo en la línea pedagógica, precisamente a favor de la perspectiva decroliana, Van Huffel nunca colaboró con este importante puente entre el Viejo Continente y Costa Rica. Ignoro si de por medio hubo razones de tipo ideológico o motivos personales.

Hilda Chen Apuy Espinoza comenta de esta época que: "eran los tiempos dorados en que el bachillerato era muy fuerte". La evaluación implicaba una parte oral y otra escrita, con dos idiomas, inglés o francés. Si uno escogía la segunda opción tenía un examen oral con René Van Huffel: consistía en la lectura de un texto y su posterior comentario. La destacada profesora recalca que la metodología era esencialmente auditiva, a veces repetitiva: constituye el recurso mnemotécnico que ha demostrado su mérito durante generaciones de gente con vasta cultura, con un oído 
cultivado y con una memoria prodigiosa. Meses antes de morir, Álvaro Bolaños, notorio alumno suyo de los años treinta en el Liceo de Costa Rica, recitaba todavía "trois jeunes garçons partaient dans un village...”. Su examen de bachillerato consistía esencialmente en leer y comentar un texto, ante este caballero "muy fino, muy culto", todo desde luego sin multimedia ni diapositivas ni powerpoint pero a la larga no menos eficiente.

Las señoras Delfina Collado y Flory Chaves, con sumo entusiasmo y gratitud testimoniaron del Profesor Van Huffel en la antigua Escuela Vitalia Madrigal, ubicada entonces al lado del Colegio de Señoritas. Señalan que el profesor, en esos años, era galán en extremo, bastante nervioso, siempre muy activo. En lo físico, se visualiza como delgadito, de ojos claros de pelo castaño canosito. "Un maestro de maestros", por su paciencia y por ser al mismo tiempo profesor de historia. Cuenta doña Flory que él le regaló un libro en francés sobre Roma y les enseñó de todo sobre Europa, más allá de fronteras. Llama la atención entonces la transmisión, de lo que podríamos llamar "lengua y sociedad". Si bien no hablaba constantemente del "Viejo" Mundo, a sus alumnos les abrió un panorama amplísimo como sólo un mentor lo puede hacer. Recalca doña Flory que "su espíritu pudo viajar en alas de la imaginación a ese continente que es luz y paradigma para los demás pueblos de la tierra". Pero también está, sobre todo la transmisión de valores. Años más tarde, ya adolescente la misma interlocutora, Don René les recalcaba en la Alianza Franco Costarricense que había que tener modelos. Fue allí donde estudiando los clásicos de la literatura francesa y la historia de Francia, ella pensó en un tipo de mujer que pudiera hacer suyo. "Me abrió el horizonte a la cultura. Me ha transformado la vida; desde entonces yo no encajaba en este país”, señala, casi con veneración.
Una característica, se puede decir permanente de René Van Huffel, a lo largo de estas décadas, es que, como buen "alcohólico del trabajo" (por sus orígenes flamencas), en cada época retratada, se perfilan cantidad de estudiantes también que él tuvo ya no en el circuito formal, sino a título privado, en horas diversas. Caso connotado lo constituye el Doctor Juan Guillermo Ortiz. Gracias a la amistad que su padre, abogado, poeta y europeizado ${ }^{27}$, cultivaba con don René, el futuro creador del renombrado "Hospital sin paredes" asistió a clases privadas durante gran parte de 1941. Como tantos otros alumnos regulares del Colegio Seminario, el joven había recibido allí clases de francés (por parte de un buen profesor alemán, por cierto), pero con énfasis en lectura y gramática, allí donde el enfoque "Van Huffel" siempre estaba más del lado de lo oral. Como muchos también, gracias a ese refuerzo, además de la empatía que a todos aseguraba el Maestro, el estudiante pasó su bachillerato con nota sobresaliente.

Destaca también la dimensión socialmente comprometida de Van Huffel y su esposa. Señala la misma informante que ella, por ser inteligente y buena estudiante, recibió una especie de beca de doña Victoria, una persona que califica como "muy exigente, muy generosa y de formación humanística". En la práctica, esa subvención consistía en varias horas a la semana completamente gratis, de parte de don René. No, no pretendo una hagiografía, pero esa descripción, llena de sinceridad y de gratitud de los años cuarenta, demasiado recuerda, por ejemplo el criterio de Hilda Chen-Apuy, para los años anteriores y anticipa lo que confirmará, por ejemplo Rolando Mendoza respecto de los años cincuenta.

En pintorescas evocaciones de sus años mozos en el Liceo, Walter Hernández le dedica unas páginas a su maestro de francés. Retoma elementos señalados, como que "su gran capacidad y facilidad para 
enseñar, unidas a una infinita paciencia, hacían sumamente agradables y provechosas sus lecciones". Luego, vuelve la insistencia sobre la pronunciación, con la frase que no es del profesor sino de chiste común: "si quieren pronunciar bien el francés, imagínense que tienen una papa caliente en la boca". Sigue una reveladora referencia al hecho de que, todavía al final de los años cuarenta, don René Van Huffel "se complacía en narrar episodios de su juventud en Bélgica en ameno y pintoresco lenguaje": manifiesto refuerzo del leitmotiv de la oposición a lo guerrero que aparece en el profesor desde los años veinte. Elemento nuevo es el hecho de que "le gustaba, al igual que a don Charles Borel (...) hacer excursiones en el campo con los liceístas, quienes disfrutábamos a lo grande de su compañía”. Por último un detalle, nada insignificante de metodología: "nos divertíamos con (...) sus alegres y nostálgicas canciones, cantadas en francés ${ }^{28}$. ¿Quién ha dicho que la docencia es aburrida? Por lo visto el docente y sus pupilos se la pasaban muy bien.

También era alumno, entonces, el celebrado caricaturista Hugo Díaz quien lo inmortalizó vía su talento ${ }^{29}$. Este recalcaba también la insistencia en la comunicación oral, de parte de don René, utilidad que comprobó cuando estuvo en Francia. Las clases se daban alrededor de unidades temáticas, como "las ocupaciones", recuerda. Esa insistencia en lo directamente motivador y en la capacidad del diálogo fueron constantes en el maestro. Por lo demás seguía destacando por su corrección en el hablar y vestir así como en la modestia de su tren de vida. El método del ósmosis debería seguir de patente actualidad. Ningún profesor de entonces tenía carro.

\section{Los años cincuenta: forja de más y más generaciones}

Aparte de estar el la vanguardia cinematográfica del país, Van Huffel también desempeñó un papel vital en el surgimiento de otra institución de peso en Costa Rica: al regresar Jorge Astúa a la patria (julio 1949) se reunió con el Sr. André Joubert, Encargado de Negocios de Francia. Se hicieron las gestiones para crear aquí una sucursal de este centro cultural. "Instalado primero en la Calle 19 en el Barrio Aranjuez de San José, hoy Hospital Dr. Calderón Guardia. Después fue en el local de los altos de "La Esmeralda", frente al Sagrario de la Catedral, que pasó a ser un centro de enseñanza. Van Huffel y la Srta. Renée Cabezas Duffner serían los primeros profesores a quienes se unieron José Antich y la Señora"30. Pero no es exagerado afirmar que, sea con su labor docente formal en el aula, sea con sus clases privadas, entonces ya de tres décadas, don René hace rato era un auténtico precursor de la Alianza, en el sentido de vehículo de cultura europea vía la lengua francesa.

En el Liceo de Costa Rica (donde el Director era Ramiro Montero, formado en Bélgica) hubo una "Promoción René Van Huffel". Destacado biólogo después, Rolando Mendoza es de la graduación de 1957 de esa entonces prestigiosa institución. Aquel "profe" belga era simpatiquísimo, señala. "Mirre (sic) Mendoza, aprenda fonética". Insistía muchísimo en ese aspecto y en la destreza a nivel de conversación. Al él se le aplica lo que Shaw señala en Pigmalion: "The French... pronounced properly". Según Manuel Antonio Quirós, guardaba un acento un tanto duro, probablemente flamenco, sin tener francés como lengua materna. Existía también el aula "Van Huffel", un salón angosto, pero con decoraciones de cultura francesa: el Mont Saint Michel, la Torre Eiffel, etc. "Estábamos muy bien preparados para el examen de bachillerato", recalcan todos. Continúa el colega Mendoza: "en las pruebas, todos pasamos con 10. Don René daba lecciones poligrafiadas sobre temas: "Le matin", etc. Sus alumnos impresionaron en una recepción francesa (Embajada) a las del Colegio de Señoritas". 
Don René adquirió después un carro pequeño, europeo, con el motor trasero. Le metieron azúcar vía el tapón de gasolina, por lo que se trabó. ¿Será una broma de mal gusto de alumnos repitentes? Es que lo de rigor entonces era ser exigente, nada "alcahueta" como ahora. "Portarse bien y estudiar", era la norma. No habían llegado todavía los tiempos del temor al trauma. Van Huffel seguía siendo muy formal. Infundía respeto pero también amistad, era exigente pero se hacía querer. Siempre prevalecía la pedagogía, la de Erasmo ("il faut que le courant passe") y de Decroly (la méthode globale). El maestro seguía escribiendo sus textos en la pizarra (conviene recordar la escasez de medios); pero su letra era bonita, porque la caligrafía era todavía algo que se enseñaba y se recalcaba.

En un informe oficial leemos: "Marzo de 1953. Empecé a trabajar en la antigua Facultad de Letras impartiendo el curso de francés conduciendo al certificado de Capacitación para la enseñanza del francés en la Enseñanza Media. Dichos cursos de dos años cada uno se dieron en los años: 1955, 1956, 1957 y en 1958 hubo uno, de verano patrocinado por la Universidad (no por el Ministerio de Educación) que condujo también a la obtención del Certificado mencionado. 1957-1958. Fui encargado de la Cátedra de Literatura Francesa para los estudiantes de tercer año de Filología que seguían con el régimen de la antigua Facultad de Letras. De 1957 a 1966. Profesor de Francés (Gramática) en la Facultad de Ciencias y Letras y de Metodología del Francés en la Facultad de Educación. En total catorce años de servicio docente en la Universidad"31.

\section{Un árbol que se muere en pie, en la Universidad de Costa Rica}

Al filo de los años setenta, teniendo entonces casi la misma cantidad de años,
René Van Huffel no pensaba pensionarse, como sí lo hace ahora la mayoría con diez o hasta veinte años menos. Después de cuatro décadas de laboriosa presencia en el país, el viejo roble seguía en la tarea diaria. Por lo demás, gozaba de una salud buena $^{32}$. Según una acción de personal, de marzo 1967, "continúa en su cargo como Director del Departamento de Lenguas Modernas", con un sueldo de $\varnothing 3.168$ colones. Es el primer director del departamento entonces de "Idiomas extranjeros" (hoy: de Lenguas Modernas). Esta elección causó algún revuelo en la Escuela. Consta una carta de veinte alumnos (casi todas mujeres), dirigida al entonces Decano de Ciencias y Letras ${ }^{33}$, en apoyo de Van Huffel, cosa concretada en marzo 1965. La misiva contiene varios "considerandos" de interés, específicamente a nivel de currículo: se recalca que no se puede olvidar que también ha sido, don René profesor de inglés en Secundaria 34 ; en seguida, que "su afán de superación lo ha llevado a prepararse en instituciones europeas y mejicanas y a hacer viajes de observación anuales a Estados Unidos". Es una razón académica un tanto débil, porque su hija vivía por allá. El otro argumento sí tenía su peso intrínseco y se comprueba como tesis a lo largo del presente escrito: "que ha sido uno de los pioneros de la enseñanza de los idiomas extranjeros en Costa Rica". Lo cierto es que la elección de subdirector por un año, celebradas el 7 de diciembre de 1963, Van Huffel ganó con 7 votos contra 1 a la Doctora Zúñiga (seguramente su propio voto ${ }^{35}$. Siempre se mantuvo una relación tensa con ella, por parte de ella, por cierto.

Muchos recalcan una constancia en su pasar por este terrenal mundo: Van Huffel, también en esos años postreros de su vida era un caballero muy fino, muy culto, muy servicial. En su ficha de la universidad aparecen otros datos personales, no mencionados hasta el momento: su cédula costarricense $\mathrm{n}^{\circ}$ 46654, su apartado 977, su teléfono: J6758 ${ }^{36}$. En estos años sigue 
también en la Alianza. Allí, Jack Wilson (que entró a trabajar en U en 1961) es alumno de él en curso de conversación. Don René preparaba todos los materiales que usaba en clases. Tenía fama de ser el mejor profesor de francés del país. Merecer ese calificativo no era fácil, no solo por ser extranjero, a pesar de la nacionalidad adquirida. No solo había que ser bueno, porque los había malos ${ }^{37}$ ), sino que el profesorado, en perífrasis a la frase de Renán sobre la nacionalidad, es un referendo de todos los días.

La universidad hacía honor a su nombre, por lo universal, con profesores foráneos como Pierre Fouché, Gerhard Sander y Alain Veillard (Historia), Olivier Biberstein, Emile Moirin (francés), Antonio Balli (italiano con estudios en Bélgica), Jack Wilson norteamericano, en lingüística), Roberto Saumells. Desde luego, también había ya profesionales costarricenses, a mucha honra, como Guillermo Malavassi, Rose Mary Karpinski, Víctor Brenes, Enrique Góngora, Manuel Antonio Víquez, Carlos Meléndez ${ }^{38}$ y otros. De reciente origen extranjero, pero creando la nacionalidad con toda honra, había que mencionar a Hilda Chen Apuy, a Elmer Bornemiza. Había que añadir dentro de este tercer grupo a René Van Huffel por haber renunciado, décadas antes, a su nacionalidad de origen. Este ambiente de ciudadanos del mundo, de cosmopolitismo como el que profesaron Brenes Mesén y Omar Dengo, es el que se echa de menos en el siglo XXI, para la universidad costarricense, porque las ideas no pueden tener fronteras.

En la Facultad de Ciencias y Letras (después de la Reforma de 1957, llamada simplemente "Letras"), Van Huffel atendía diversas cátedras, en la carrera de francés titular. Daba gramática francesa (el curso L-120, con 4 créditos). También allí el profesor llevaba todos los materiales. Era gramática normativa. En la Facultad de Educación se encargaba de "Métodos y Práctica docente", en francés. En ambas facultades como tales se perdió casi todo rastro documental respecto de lo investigado. En el primer caso todavía se puede invocar un tremendo incendio; en el segundo, el calificativo de dejadez y de falta de perspectiva histórica, quién sabe si no son calificativos pertinentes.

No se sabe de publicaciones de Van Huffel fuera de su manual de francés y la traducción del prólogo en el libro de Bourla, factores, comentados. Cuando él era profesor, no se exigían esos elementos curriculares, ahora vitales. Había un sueldo igual. Pero lo que siguió primando era su sello personal. No soportaba que una persona fuera inepta y al respecto, como buen nórdico, no ocultaba sus sentimientos. Varios estudiantes y después colegas lo califican como recto. Era simpático y hasta chistoso, pero un tanto burlón con los estudiantes más flojos. Vivía sin lujo.

\section{Un puente indiscutible}

Nacido prácticamente con el siglo, tantos años de entrega a una profesión agotadora, si se toma en serio, lo marcaron. El 1 de marzo de 1970 y por la entonces vigente edad reglamentaria, le llegó una especie de sentencia: el cese de funciones. Lo debe haber sentido doblemente porque ese documento iba firmado por la Doctora Virginia Zúñiga Tristán, su sucesora. Se despidió correctamente de todo el mundo y se fue para la casa, a fumar... En total, desde la fecha de su ingreso en el claustro universitario, contabilizó diecisiete años, de los cuales prácticamente una década como director del Departamento de lo que ahora sería la "Escuela de Lenguas Modernas". Si a esa carrera se añaden treinta años de docencia a nivel de secundaria, se contabiliza prácticamente medio siglo al servicio de Costa Rica.

René Van Huffel es el tipo de profesor de idioma y de cultura que todavía se necesita: nada nacionalista, verdadero cosmopolita, en el sentido de Brenes Mesen ("soy 
ciudadano del mundo, mi compatriota es el hombre"). Luis Alberto Monge, como muchos, pensaba que era francés. Nadie puede discutir su valor como "visagra cultural" específicamente con lo europeo. Con muy buen tino de síntesis y de valoración histórica, que todo el mundo le reconoce, Marta Castegnaro lo cataloga como "el rector de la enseñanza del francés en el país de estos años". Discípulos suyos, fuera de los aludidos, fueron, por ejemplo, también Don Alberto Cañas, el Dr. Guillermo Ortiz y tantos otros.

\section{Notas}

1. Un día habrá que estudiarlos también específicamente, pienso en Hernestina...(no se entiende el impreso).

2. Me refiero por ejemplo a doña María Eugenia Dengo, que escuchó ese calificativo. En lo personal opto más bien por la interpretación de una salida como objetor, porque de lo contrario difícil sería que las autoridades belgas lo tomaran en cuenta todavía, después, como se verá.

3. Ver carta de los estudiantes en apoyo de su candidatura a la Dirección del "Departamento de Idiomas Extranjeros", del 30 de noviembre de 1963. (Documento en archivo del Consejo universitario).

4. Me baso en información en la caja 6, del Fondo "Manuel María Peralta", en los Archivos de Zapote.

5. Dedicaré un informe especial a la mission Rouma, que pasó por Costa Rica en mayo de 1922: pero no ubico allí todavía directamente a Van Huffel. Al parecer llegó recién en 1923, con lo que puede haber colaborado en el seguimiento de esa mission.

6. "Chambre de Commerce Belgo Latino-Americaine (33, Rue Ducale, Bruxelles)". Se trata de una iniciativa creada a raíz de la devastación alemana y el consecuente bloqueo inglés contra Alemania en Bélgica. Ambos factores dejaron Bélgica arruinada al final de la guerra. En la Caja 49 del "Fondo Peralta", en los
Archivos de Zapote, se encuentra al respecto un "Mémoire du Gouvernement du Roi", fechado en Le Havre en 1917, así como referencia a la Commissión for Relief in Belgium que se creó para remediar a tal situación.

7. Este compatriota vino antes y se naturalizó el 30.11.1915, sospecho que influenciado por el contexto bélico. Todavía existe la "Coin Corporation S.A. en Barreal de Heredia.

8. Mis aseveraciones van debidamente documentadas. A esos señores Deliens, Van der Laat y Loots, todos compatriotas de Van Huffel entonces residentes en Costa Rica convendrá igual dedicar estudios por aparte.

9. Alguna gente, entre otros, don Luis Alberto Monge y el Dr. Omar Acuña, sospechan también de la existencia, en Costa Rica, de una hermana.

10. En San José, frente al hotel Talamanca existe todavía un edificio "Miguel Mena y Cía", entonces un floreciente comercio de telas, vinos, etc.

11. La aseveración la pone en una de sus crónicas del Día Histórico en La Nación. Al conjunto de este grupo, de más de ochenta estudiosos en Bélgica en los años veinte, dediqué un estudio completo. Ver: "Una generación única de profesionales ticos, formados en Bélgica", Herencia, volumen $7-8, \mathrm{n}^{\circ} 1-2,1995-96$, pp. 15-26.

12. Información del Consulado de Costa Rica, en Cherbourg, Francia, con fecha 29 de enero 1930 , en la caja 36 a nombre del citado diplomático en los Archivos Nacionales, en Zapote.

13. P. 3, en el citado libro. Conste que don Guillermo no era precisamente tampoco un hombre profesional en esta rama, siendo que más bien estudió en Francia y Bélgica en ciencias médicas.

14. El lector más interesado en esta problemática teórica podrá acudir, por ejemplo, a mi trabajo: "Para una globalización interior: revaloración del término a partir del método Decroly", Estudios Pedagógicos, Universidad Austral de Chile, $\mathrm{n}^{\circ} 23,1997$, pp. 65-74. Sobre el Prof. Salazar saldrá un trabajo mío en la revista Escena, de Costa Rica en el 2004. Sobre los otros mencionados y la incidencia decroliana en ellos, tengo varias monografías en preparación. 
15. Frase recogida de unos cometarios del Profesor en "Campus", UNA, noviembre del 2000. Sin mencionar directamente a Decroly, así es como el discípulo identifica su propia filosofía educativa, la cual, cabe recordar profundizó directamente en la cátedra del Dr. Decroly, en el Bruselas de fines de los años veinte. En la revista Herencia, de la Universidad de Costa Rica saldrá en 2004 una biografía de Marco Tulio Salazar, con énfasis en su provechosa relación con Bélgica.

16. Ref. a "Señorita Vitalia Madrigal, Directora de la Escuela Superior de Niñas n ${ }^{\circ}$ "), ver Repertorio Americano, vol. 12, n²2, p. 317.

17. El dato corresponde con la investigación del Sr. Cor Teunissen en los libros de naturalización en el Registro Civil, tomo "ac p. 210", con una primera inscripción en 1924.

18. En caja 19 de la documentación a nombre de Manuel María Peralta, en los Archivos de Zapote, con nota del 27 de diciembre de 1929, se da la nómina de profesores extranjeros de segunda enseñanza en el país: Henri Pittier, Lucie Bouthier, Juan A. Menigua y Louis Appel (de Francia), Eginhard Menghius y Paul Schauffelberger (de Alemania), Henry Mc Ghie (Jamaica), José Figuer del Valle (España), Ines de Madrigal (Estados Unidos).

19. Walter Bolandi se encuentra en el país desde antes de abril de 1927 (Ver alusión en Káñina, revista de la Universidad de Costa Rica, vol. III, julio-diciembre $1979, \mathrm{n}^{\circ} 2$, p. 122).

20. Ver un artículo del mismo Van Huffel en el Diario de Costa Rica, del 11 de noviembre de 1930, p. 6. Ver también referencias en el libro "El espejo iluminado" (2003), historia del cine en Costa Rica, por María Lourdes Cortés.

21. Surge una curiosa interpolación cinematográfica por parte de los dos extranjeros (Bertoni y Van Huffel) en esta producción. Ver mi artículo: "El retorno de ... René Van Huffel", en El Candil, revista del Ministerio de Cultura, Juventud y Deportes, Vol. 1, enero-abril 1966, $\mathrm{n}^{\circ}$ 2 , pp. 64-68. Retomado parcialmente, con el título "Entre la identidad y la transculturación. El caso Van Huffel”, en la Revista Escena, Universidad de Costa Rica, volumen 36-37, año 18-19, 1995-96.

22. En Alsacia, a raíz de la guerra de 1870, sellada con la derrota de Francia contra Alemania, a un viejo maestro le prohíben dar clases de francés. Su última clase rezuma amor por la cultura de habla francesa.

23. Está por estudiarse la relación de belgas u originarios de allí, como Van Huffel con ese importante Comité. Existen referencias desde 1917. Tenía un periódico "L’Amérique Latine" en el que el Marqués de Peralta colaboró. En 1928 su dirección era "France-Amérique, 9 et 11 Avenue Victor-Emmanuel III, Paris VIII.

24. Libro Azul del año 1940, en posesión del Lic. Milton Arguedas, Heredia.

25. Ver, de mi autoría: "Yvonne Clays: entre el rescate y el desagravio para una Primera dama tica y belga", en Revista Nacional de Cultura, San José, Costa Rica, nํ29, mayo 1997, pp. 4356. Doña Ivonne estaba en sus últimos años y aparte de que por su estado de salud no había oportunidad de preguntar tanto respecto de puentes innumerables, entonces, con Bélgica.

26. Ver trabajos del suscrito, como "Bélgica en el Repertorio Americano: Índice completo y comentado de referencias "desde y sobre Bélgica” en la revista costarricense dirigida por Joaquín García Monge, de 1919 a 1958”, aceptado para publicación en Repertorio Americano, Revista de la Universidad Nacional, $n^{\circ}$ 9-10, enero-diciembre 2000. Ver también "El cosmopolitismo de Joaquín García Monge: Bélgica en el Repertorio Americano", ibidem.

27. El Lic. Rafael Ortiz estuvo por tres años en Francia y Bélgica, a principios de los años treinta, después de la muerte de don Manuel María Peralta, citado. Este dato refuerza la pista en el sentido de un conocimiento mutuo entre Peralta y Van Huffel, como apuntado. Fue el padre Ortiz el que redactó la propuesta de ley por la cual otros colegios que el de Costa Rica (como el Seminario y el Colegio Sión, ambos profundamente europeizados por cierto, tuvieran también derecho a dar títulos de bachiller. Don Teodoro Picado pasó este escrito a la Asamblea y el Presidente Calderón refrendó la ley.

28. Hernández Valle, Walter: Años de primavera, Editorial Costa Rica, 1995. Citas de la página 161.

29. Ver en el mismo libro citado, de Hernández.

30. La Nación, 29.01.1990. 
31. Ver el expediente a nombre de él en la Oficina de personal, Universidad de Costa Rica (UCR), setiembre de 1966 .

32. El acta de la Asamblea universitaria $\mathrm{n}^{\circ} 82$, de 1961 (UCR) menciona una operación delicada.

33. Archivo del Consejo Universitario, carta con fecha 30 de noviembre de 1963.

34. Dio clases de inglés en la Escuela de Comercio Manuel Obregón, en 1940 (El libro azul de este año lo señala erróneamente como "Renée") y en el Centro Cultural Norteamericano; según don Florentino (dueño de la Librería Acrópolis), en el Liceo de Costa Rica fue profesor de inglés, pero solo un tiempo como sustituto del profesor titular.

35. Ver entre otras las actas del Consejo Directivo de la Facultad de Ciencias y Letras, sesión 349 .

36. Anacronismo total: en la última guía telefónica del año 2004, todavía se señala claramente: "Van Huffel Dedobbeleer René a9 335 (Barrio Amón; Avenida 9 este \# 335) 221-1326”. ¿Los muertos gozan de buena salud?

37. La documentación universitaria disponible refiere muy negativamente, por ejemplo, a otro europeo, el profesor Alain Veillard-Baron.

38. Don Carlos nunca fue alumno suyo, pero sí, de confesión propia, tuvo mucha amistad con él.

\section{Referencias bibliográficas}

Alianza Francesa (de Costa Rica): Un siglo, una casa, Libro conmemorativo de la casa de esta agrupación cultural, impreso en La Nación, abril 1996. Bajo el título de "Los fundadores", contiene, pp. 68-69, un párrafo interesante sobre René Van Huffel.

Ferreto Adela, Cristian Rodríguez, Carlos Luis Sáenz, Emma Gamboa, Rafael Cortes: Omar Dengo visto por cinco discípulos, Ciudad Univ. 1978, 190 pp.
García H., Roberto: "El Retorno: historia y vivencias, en Luces, cámara, acción, editado por María Lourdes Cortés, Editorial Universitaria, 2000, pp. 169-178.

Hernández Valle, Walter: Años de primavera, Editorial Costa Rica, 1995. Las páginas 158-161 se ocupan específicamente de don René.

Universidad de Costa Rica: Departamento de Personal, Archivo personal de René Van Huffel, años sesenta.

Valembois, Víctor "El retorno de ... René Van Huffel”, publicado en El Candil, revista del Ministerio de Cultura, Juventud y Deportes, Vol. 1, eneroabril 1966, n 2, pp. 64-68. Retomado parcialmente con el título "Entre la identidad y la transculturación. El caso Van Huffel”, en la Revista Escena, Universidad de Costa Rica, volumen 36-37, año 18-19, 1995-96.

\section{Informantes:}

Marie Thérèse Baudry Drabber de Urruela: entrevista el 16.08.99 y conversaciones a fines del 2000

\section{Marco Tulio Salazar}

Isabel Montero (y su mamá Joyce): amigos ¿?

Fabio Fournier: tel : 221-13-39; 22282-96, 221-5741

\section{Ana Lucía Salazar}

Paule Mulhendorf de Ortiz

María Eugenia Dengo de Vargas, en diciembre del 2000 
- Margarita Macaya

Hilda Sancho, Dra.

Rosario Solano (amiga de YC)

Luis Alberto Monge, 17.01.99

Elsa Orozco, tel 221-60-20 (sugerencia de Ma. Eugenia Dengo)

- $\quad$ Hugo Díaz, ver: Alexandre de Simonne, esposa de Miguel Chaves, 2218610, tiene cierto parentesco.

Otto Calvo Coin, entrevista el 9.12.98 240-8028

- $\quad$ Rodolfo Francés, el 6-8-98

- $\quad$ Aminta de Quirce (asunto Loots)
- José Antich: "notre plus ancien professeur" 225-6287

Carlos Mena Ugalde: 14.09.1995

Miriam Francis, el 05.02.96

Carlos Meléndez, el 6.3.96

Flory Chaves, el 4.9.96 y correspondencia en noviembre 2000

Juan Antonio Barzuna, 1997

Sra. Somarriba, fines del 2000 (vía Manuel Antonio Quirós)

María Lourdes Cortés (31.08.00)

Jessie Montejo de Orlich (enero 2004)

Jeannette Gurdian (febrero 2004) 